\title{
SCIENCE
}

A WEEKLY JOURNAL DEVOTED TO THE ADVANCEMENT OF SCIENCE, PUBLISHING THE OFFICIAL NOTICES AND PROCEEDINGS OF THE AMERICAN ASSOCIATION FOR THE ADVANCEMENT OF SCIENCE.

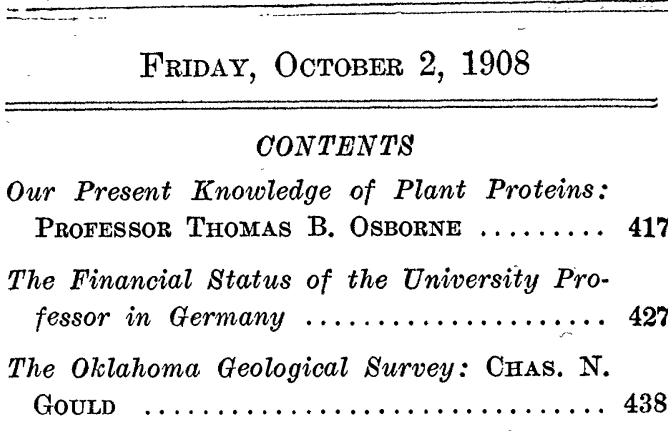

The International Congress on Tuberculosis. . 438

Organization of a Biological Board ...... 439

Scientific Notes and News ........... 440

University and Educational News .......443

Quotations:-

An Educational Paradox .......... 445

Discussion and Correspondence:-

Mathematics for Engineers: Professor W.

S. FrankurN. What can be done to Enhance the Value of the Work of the Bureau of Standards to the Chemical Industries?

LAUnCELot ANDREws ............4446

Scientific Books:-

The Work of John Samuel Budgett: W. Clerke's Popular History of Astronomy during the Nineteenth Century: SToRRs B.

BARRETT .................. 452

Scientific Journals and Articles ........ 454

Special Articles:-

Degeneration, Albinism and Inbreeding: Professor Chas. B. Davenport. The Question of Cyclopia, One-eyed Monsters:

Dr. C. R. Strockard ........... 454

MSS. Intended for publication and books, etc., Intended for veriew should be sent to the Editor of Scresce, Garrison-onHudson. N. Y.

\section{OUR PRESENT KNOWLEDGE OF PLANT PROTEINS ${ }^{1}$}

To the biological chemist few substances present so many features of interest as the proteins of plants. These lie at the very foundation of the nutrition not only of plants but of animals, and from them are derived a multitude of products directly connected with physiological processes. The study of the chemistry of plant proteins, although it early interested several of the leading chemists of their time, has received in the aggregate so little attention that to-day our knowledge of this subject is but slightly advanced beyond what may properly be called a beginning. How slow the progress has been may be shown by a brief review of the literature that is on record.

\section{HISTORICAL}

In 1746, Beccari announced his discovery of a peculiar substance which he obtained by washing wheat flour with water, that had all the properties which up to that time had been considered to be characteristic of animal life only. This substance, which we now know to be wheat gluten, appears to have been for more than fifty years the only form of vegetable protein that was known, for Beccari failed to obtain similar products from other seeds.

In 1805, Einhof discovered that a part of the gluten of wheat was soluble in alcohol, and he described the existence of similar proteins in rye and barley. Einhof

1 An address delivered before the American Chemical Society at New Haven, Conn., July 1, 1908. 
overlooked the fact that only a part of the gluten of wheat was dissolved by alcohol, and he considered this property to be characteristic of all plant proteins except the "Eiweiss," which he obtained by heating the aqueous extracts of seeds and other parts of plants. When, therefore, he later discovered in leguminous seeds another form of protein which was not soluble in alcohol, but had in pronounced degree the properties of "animal matter," he assumed that he had obtained a substance belonging to a distinctly different group but yet related to the gluten or "Kleber" that had been found in other seeds.

Taddei, in 1820 , showed that only a part of the wheat gluten was soluble in alcohol and he applied distinctive names to each part; gliadin to the substance soluble, and zymom to that insoluble, in alcohol.

From this time, chemists were more and more attracted to the study of vegetable proteins, and among those thus engaged are found many of the most distinguished chemists of the earlier part of the last century, such as Berzelius, Dumas, De Saussure, Boussingault, Liebig and many of his pupils.

In 1841, Liebig reviewed the work done in his and other laboratories on the properties and composition of plant proteins. The state of knowledge which then prevailed respecting this subject is well illustrated by the following quotation from his review :

Another, in number very limited, class of nitrogenous compounds is very abundantly distributed. There are four of these substances, of which one occurs, without exception, in all plants, while the others are only constituents of certain families of plants. These are the nitrogenous food substances properly known under the names of Vegetable "Eiweiss," Pflanzenleim and legumin. . . These substances, to which a fourth must be added, which $\mathrm{I}$ will name Pflanzenfibrin, are the true food substances of the plant-eating animals.
In discussing these four proteins, Liebig asserted that each was identical with the protein of animal origin bearing the corresponding name. The identity of legumin with milk casein was claimed and this protein he therefore named plant casein.

The work undertaken by Liebig was continued for twenty years or more by Ritthausen, who was one of his pupils. Ritthausen, in 1860 , began the first serious study of these important substances and devoted much time and care to the production of preparations of the highest attainable purity, and to accurate determinations of their ultimate composition. His work greatly extended the scope of the prevailing knowledge of the plant proteins, and made it plain that these substances exist in much more diverse forms than had before been supposed. He also added much to our knowledge of the decomposition products of vegetable proteins by showing that they yielded many substances already obtained from proteins of animal origin, and discovered glutaminic acid which is now recognized as a constituent of practically all proteins, whatever their origin. He was also the first to obtain aspartic acid from the products of protein hydrolysis.

In 1877 Hoppe-Seyler and his pupil Weyl applied to seeds the then recently developed method of extraction by solutions of neutral salts. They showed that a large part of the protein of a number of different seeds was soluble in such solutions, and had the properties of the socalled globulins of animal origin. While the experimental work of these investigators was hardly more than qualitative and of very superficial character, the conclusions which they drew and the criticisms of Ritthausen's work which they put forth were generally accepted as final by most physiologists, and threw it into general discredit. 
Although Ritthausen afterwards showed that a large part of many of his previously described preparations, which had been obtained by extraction with dilute alkalies, was soluble in solutions of neutral salts, and that the composition of many of the proteins which he had previously analyzed was the same as that of preparations obtained by extraction with solutions of sodium chloride, nevertheless physiologists continued to repeat the criticisms of Hoppe-Seyler, and the work of Ritthausen failed to receive the recognition which it deserved.

\section{REVIEW OF THE WRITER'S WORK}

Since Ritthausen ceased his work with vegetable proteins little has been done in this field outside of my own laboratory. It is true that from time to time papers have appeared dealing with special questions in the chemistry of these substances, but no other connected and extensive investigation has been described, and as the work which I have been doing during the past twenty years has now reached a point where it can be profitably reviewed, I propose to take up some of its more important features and briefly discuss them.

As Ritthausen's researches were far from exhaustive and left the subject in such a state of confusion that it was impossible to form definite conclusions respecting much that he had described, it seemed best to me to direct attention chiefly to those seeds which had been previously studied by him and by others, and to try to clear up the existing uncertainties, rather than to add to them by describing new proteins. As a result, we now have about twenty-five different proteins of vegetable origin, the important characters of most of which have been studied by all the means at present available. These proteins appear to represent the different types to be found in seeds and are, I think, sufficient in number to form a suitable foundation for the future study of their chemistry. All of these are constituents of seeds. A few of them represent constituents of the physiologically active embryo, but the majority represent the reserve food protein of the endosperm, and serve not only for the nutrition of the growing seedling, but also for the nutrition of men and animals. Of the protein constituents of other parts of plants very little indeed is known.

\section{CHEMICAL INDIVIDUALITY OF PROTEINS}

In considering the position of our present knowledge of the seed proteins, the question of chemical individuality should first be considered. We are now well past the time when agreement in solubility, ultimate composition and color reactions, are to be accepted as evidence of the identity of two preparations of protein. It is not necessary to explain why it is at present not possible to demonstrate the chemical individuality of any single protein, for the reasons are evident to all who will give this question the slightest consideration from the standpoint of the organic chemist. While it is not possible to establish the individuality of any protein, it is possible to show differences between the various forms which can be isolated, and to establish a constancy of properties and ultimate composition between successive fractional precipitations which give no reason for believing the substance to be a mixture of two or more individuals.

On the basis that agreement in ultimate composition affords no evidence of identity of two similar proteins, but that distinct and constant differences in composition are conclusive evidence that they are not alike, I have endeavored to differentiate the several seed proteins that I have studied, and have since subjected them to careful 
comparisons in respect to their physical properties and the proportion of their decomposition products, so that those which are alike in their more apparent characters have been still further distinguished from one another. Whether these are in fact chemical individuals, must await the development of new methods of study. For the present they must be accepted as the simplest units with which we can deal.

SUITABILITY OF SEED PROTEINS FOR A STUDY OF PROTEIN CHEMISTRY

The various proteins thus established furnish material for further study, and are characterized by wide differences not only in physical properties, but in the proportion of their decomposition products. They can be prepared in large quantity in a high state of purity, and, being a part of the reserve food stored up for the nutrition of the developing embryo, are by nature more stable than the animal proteins which form a part of physiologically active tissues. Furthermore, they are not associated with tissues and fluids rich in other forms of protein from which they are to be separated, and they are mostly obtained in the form of dense precipitates, often crystalline, which are little inclined to adsorb other substances from which they can afterwards be separated with difficulty. Although associated intimately in the seed with many forms of soluble and insoluble carbohydrates, they can, in many cases, be separated from every trace of the latter, as is shown by appropriate reactions.

It is my firm belief that a careful examination of them will ultimately afford a better knowledge of the chemistry of proteins in general than can be obtained from proteins of animal origin. Although the problems immediately connected with the animal proteins are of greater importance to physiology than those at present recog- nized as connected with seed proteins, there is no question but that definite knowledge of the chemistry of seed proteins will be directly applicable to many important problems of animal physiology.

THE DIFFERENT GROUPS OF PROTEINS FOUND IN SEEDS

The seed proteins for the most part can be grouped in much the same way as the proteins of animal origin, but in so doing, it is necessary to modify to some extent the requirements to which the animal proteins belonging to some of these groups are at present assumed to conform. The necessity of some scheme of classification for the proteins is recognized by all who write or teach about them, and although the present method of classifying proteins according to their solubility is wholly unsatisfactory from a purely chemical standpoint, it is practically the only one now available. On chemical grounds there is no more reason for dividing the proteins into two groups of animal and vegetable proteins, than there is for making a similar distinction between the carbohydrates. I have, therefore, endeavored to assign the various forms of seed proteins to the commonly recognized groups established for those of animal origin, and have proposed to slightly modify the definitions usually given for these groups, but only so far as this is necessary.

1. Globulins form much the greater part of the reserve protein of all seeds except those of the cereals. By globulin is meant protein soluble in solutions of neutral salts but insoluble in water. This definition does not strictly apply to many of the seed proteins assigned to this group, for these behave as globulins only under certain conditions. As these conditions prevail during the extraction and isolation of these proteins and depend on the presence of free acid in the extracts, it is important 
to consider the relations of the proteins to this acid.

The behavior of seed globulins toward acid is shown by studies made in my laboratory on edestin. Crystallized preparations of edestin, obtained by dialyzing or cooling sodium chloride extracts of hemp-seed, frequently contain protein in three forms; one, soluble in pure water and also in strong saline solutions, another, insoluble in water but soluble in strong saline solutions, and still another, insoluble either in water or in saline solutions. The proportion of these products varies with slight differences in the conditions under which the edestin is isolated, and plainly depends upon changes in the protein which take place during its preparation.

The explanation of these changes has been found in the presence of a small amount of acid extracted from the seed together with the protein. The part of the edestin preparation just referred to, which is insoluble in neutral saline solutions, has been found to be a product of the hydrolytic action of the acids of the extracts. This product is not the result of a profound splitting of the edestin molecule, for the changes leading to its formation are so slight that they can be detected only by the altered solubility. For such primary products of protein hydrolysis, which were designated "albuminates" by Weyl, I have proposed the name "protean" and for the products derived from the individual proteins, a corresponding name ending with the affix an. Thus the product derived from edestin may be called edestan. The part of the edestin above referred to which is soluble in water contains more combined acid than the part insoluble therein. The preparation, therefore, contains a mixture of salts of edestin. These edestin salts contain some of all the anions present in the solution at the time of precipitation, that salt being predominant whose free anion was most abundant in the solution from which the edestin was last precipitated. When freed from this combined acid by making the preparation neutral to phenolphthalein, the edestin is wholly insoluble in water, but soluble in neutral saline solutions. Edestin has, consequently, the properties of a true globulin. Other seed proteins behave towards acids in a similar way, except that some of them, when neutral to phenolphthalein, are soluble in water. Many of these latter behave as globulins when in the form of salts, and as they are obtained as salts by the methods employed in preparing them, I have for convenience, placed them among the globulins.

The fact that our protein preparations, as usually obtained, are protein salts is fundamental for a correct conception of their behavior under the conditions of isolation and purification, and for an explanation of many of their physiological relations.

'The seed proteins which are described as globulins, differ in some of their properties from some of those that are commonly assumed to characterize the globulins of animal origin. In this connection, however, the fact should not be overlooked that our knowledge of animal globulins is relatively small, and it is probable that further study will modify our present conception of them. It has become customary for physiologists to consider that all globulins are precipitated by adding to their solutions an equal volume of a saturated solution of ammonium sulphate, and of recent years it appears to have become an almost universal practise to designate as globulin all the protein that can be thus precipitated. This practise is unfortunate and leads to confusion, for it wholly ignores the original conception of a globulin, namely, a protein soluble in neutral saline solutions but insoluble in water. 
Globulins are commonly described as proteins that are coagulated by heat. This is doubtless true of the globulins of seeds if sufficient acid is present in their solutions. It is, however, difficult to add to the saline solutions of most seed globulins a sufficient amount of acid to cause complete coagulation on heating, for even a very minute quantity of acid in a strong saline solution alone precipitates a large quantity of the globulin.

The deportment of edestin in this respect is well illustrated by the experiments of Chittenden and Mendel, ${ }^{2}$ who showed that a saline solution of edestin was only partly coagulated by boiling, that the edestin remaining in solution could be recovered unchanged and in well-formed crystals, and that addition of acid to the solution filtered from the coagulum gave rise to a new coagulum on again heating.

2. Prolamins ${ }^{3}$ form a unique and sharply differentiated group of proteins which occur in quantity in the seeds of cereals, but not in those of any other plant yet examined. These are soluble in all proportions in alcohol of 70-80 per cent., and are not affected by boiling their alcoholic solutions, even for a long time. They are practically insoluble in water and saline solutions, but are soluble in dilute solutions of acids and alkalies.

The prolamins are better characterized, from a chemical standpoint, than any of

\footnotetext{
${ }^{2}$ Chittenden and Mendel, Journal of Physiology, XVII., p. 48, 1894.

${ }^{3} \mathrm{I}$ propose this name for the group which heretofore has been simply called alcohol-soluble proteins. The name refers to the relatively large proportion of proline and amide nitrogen which they yield on hydrolysis. The English committee on protein nomenclature has very recently proposed to call these proteins gliadins, but as this name has long been used to specifically designate the prolamin obtained from wheat it seems to me important to have a distinctive name for this group.
}

the other groups of seed proteins, for on hydrolysis they all yield a very small amount of arginine and histidine and no lysine whatever. On the other hand, they yield from 20 to 30 per cent. of their total nitrogen in the form of ammonia and also contain relatively large amounts of glutaminic acid. Gliadin from wheat and rye, and the related hordein from barley, yield about 37 per cent. of glutaminic acid, which is very much more than that found in any other protein yet examined, and zein yields nearly 20 per cent., which places it among the proteins relatively rich in this amino-acid.

Prolamins have been found in the seeds of all the cereals examined in my laboratory, namely-oats, wheat, maize, rye, barley and sorghum. That this form of protein is characteristic of the seeds of all grasses is rendered improbable by the recent report of Rosenheim and Kajiura, who found none in rice. A detailed statement of their results, however, has not, to my knowledge, yet been published.

3. Glutelins constitute a large part of the proteins of all the cereals that have been studied, and possibly occur in seeds of other kinds. These proteins are insoluble in all known neutral solvents, but are easily dissolved by very dilute acids or alkalies. Only one member of this group is known which is accessible to satisfactory investigation. This is the glutenin of wheat which forms nearly one half of the gluten. Owing to the fact that glutenin can be separated from the other components of the seed as a constituent of the gluten, it is possible to make preparations of it of a fair degree of purity.

As the seeds of the other cereals yield no coherent gluten, the protein corresponding to glutenin can not be isolated from them, for the alkaline extracts of these

- Rosenheim and Kajiura, Journal of Physiology, XXXVI., p. liv, 1908. 
seeds are too gummy to filter and the small amount of the preparations that can be obtained is very impure.

Whether glutelins are constituents of other seeds is a question not yet settled. Most seeds, when exhausted with the several neutral solvents, still contain a small amount of protein which can be extracted with alkaline solutions. It has not yet been definitely determined whether these products are residues of the other proteins extracted by the neutral solvents, or are actually different substances. It is quite conceivable that a part of these other proteins may form combinations with other constituents of the seeds which are not soluble in neutral solvents but are extracted by alkalies, and also that a part of the protein is enclosed in tissues which are dissolved by the alkali and the protein then brought into solution. . It is also possible that much or all of this protein is the result of a change, whereby a part of the protein originally soluble in neutral solvents is converted into less soluble products, such as those which have been designated as proteans. The quantity of nitrogen which remains in the thoroughly extracted residues of the seeds is small in the case of most seeds other than the cereals, and it is not probable that many of these contain much, if any, protein belonging to the glutelin group.

4. Albumins are probably present in very small amount in nearly all seeds, and in none of those that I have examined are they present in large amount. The albumin is probably a part of the physiologically active embryo, and resembles the proteins of animal origin in properties, ultimate composition and proportion of the various products of hydrolysis, more closely than do most of the reserve proteins of the endosperm. While the albumins of seeds are like those obtained from animals in the essential properties of solubility in water and coagulability by heat, they differ in their precipitation relations towards strong solutions of inorganic salts.

It is at present almost universally assumed that albumins are not precipitated by adding to their solutions an equal volume of a saturated solution of ammonium sulphate, but this is not the case with all of the albumins from seeds. Many of them are also precipitated by saturating their solutions with sodium chloride or with magnesium sulphate, in which respect they differ from animal albumins.

5. Proteoses similar to those of animal origin have been obtained from all the seeds examined, and from some, proteoses closely resembling hetero-, deutero- and proto-proteose were separated. The amount of such proteose is small in all the seeds which have come under my observation, and it is possible that all of this is formed by enzyme action during isolation of the other proteins of the seeds.

There are several groups of proteins which occur in animal tissues, which have not yet been proved to exist in plants. The most important of these are those which contain phosphorus. In the yolk of eggs and in the milk of mammals, a large part of the protein which nourishes the developing animal contains phosphorus which appears to be intimately concerned in the structure of its molecule. No similar phosphorus-containing proteins have been found in seeds, although by analogy such might be expected to occur. It has been asserted that such proteins are found in leguminous seeds, but an examination of the literature will show this assertion to be founded on very little experimental evidence. Czapek, in his "Biochemistry of Plants," deseribes the proteins of seeds as vitellins which doubtless contain phosphorus. This view, however, has no evidence to support it and is quite incorrect. The existence of nucleoproteins, that is 
of compounds of nucleic acid with protein, is a different question and involves consideration of the chemical nature of these substances as now described. The nucleoproteins are, so far as I know, always described as phosphorus-containing proteins, and the phosphorus seems to be generally considered as a constituent of their molecules. This, of course, is strictly true even if the combination be only that of a base and an acid, but from the standpoint of protein chemistry it makes a great deal of difference whether this union is that of a salt, or one in which the phosphorus-containing groups are in intimate organic combination within the protein molecule. That true nucleic acids exist abundantly in seeds has been demonstrated by investigations made in my laboratory on the wheat embryo. In these investigations a great deal of attention was devoted to the protein compounds of the nucleic acid, but all the evidence obtained indicated very plainly that these were simply protein nucleates, the composition of which depended solely on the conditions prevailing at the time of precipitation. That similar combinations exist within the embryo is practically certain, but that any of the combinations actually isolated were identical with the combinations that exist in the seed, I consider highly improbable. Whether the nucleoproteins that have been described from animal tissues are more definite and intimate combinations between the nucleic acid and the protein than are the protein nucleates just mentioned, I am not prepared to say, but I think that nucleoproteins deserve more consideration from this point of view than they have received.

Whether, or not, true glycoproteins are contained in seeds, remains to be demonstrated. That a large part of the seed proteins are entirely free from any carbohydrate yielding group, is proved con- clusively by the fact that these yield no trace of the Molisch reaction. That those that give the Molisch reaction contain a carbohydrate group as a constituent of their molecule is seriously to be questioned, for it is not possible to obtain even traces of furfurol from them.

If one considers how small an admixture of carbohydrate gives a very strong reaction with the Molisch test, it may well be asked whether this reaction is not sometimes caused by a slight contamination. The possibility of this is so great in the preparations of proteins extracted from seeds containing a great variety of carbohydrates, glucosides and nucleic acids, that conclusions drawn from the results of the Molisch reaction have value only when this turns out negatively.

In plants no representative has yet been found of the group of albuminoids which form in animals so large a part of the skeleton, connective tissues, the skin and its appendages.

Although the nucleated cells of the wheat embryo are rich in nucleic acid which closely resembles in its properties and structure the nucleic acids obtained from the nucleated cells of animals, no substances have yet been found in plants which resemble the protamines which in combination with nucleic acid occur so abundantly in the spermatozoa cells of animals. Such substances are to be sought in the pollen cells of plants, but as yet no attempt has been made to isolate them, owing to the difficulty of obtaining a sufficient supply of material, and the fact that the nucleus of the cell forms so small a part of the whole structure.

PRODUCTS OF HYDROLYSIS OF SEED PROTEINS

of the known primary products of protein hydrolysis all but one (diamino-trioxydodecanic acid, as yet obtained only from casein) have been isolated from seed 
proteins, and there is no indication that any essential difference exists in the general character of the structure of the proteins from these two forms of life. Some of the seed proteins, like some of those from animals, lack one or more of the amino-acids; and zein, from maize, lacks glycocoll, tryptophane and lysine. The crystalline glubolins, which are possibly more definite chemical individuals, have yielded on hydrolysis as complicated a mixture of amino-acids as any of the amorphous preparations. These, therefore, furnish no ground for the assumption that the several proteins, as we now know them, are mixtures of less complex substances.

Of twenty-three different seed proteins which have been hydrolyzed, all have yielded leucine, proline, phenylalanine, aspartic acid, glutaminic acid, tyrosine, histidine, arginine and ammonia. Five have yielded no glycocoll. Two yielded no alanine which could be positively identified, but did yield impure products which left little doubt but that this amino-acid was present. Four yielded no lysine, and one, no tryptophane. Four of these proteins yielded extremely small quantities of cystine, three others, none. The remaining sixteen have not yet been examined for this amino-acid on account of the difficulties encountered in separating small quantities of it. No attempt has yet been made to isolate isoleucine. If this amino-acid is yielded by the seed proteins -it will probably be found in the mixture of undetermined substances from the third fraction of the esters, which has not been converted into products suitable to weigh. Glycocoll, lysine and tryptophane are the only amino acids that have been proved lacking in any one of these proteins.

In respect to the quantitative relations of the amino-acids, the fact must not be overlooked that the determinations of many of them are to be regarded only as ap- proximations to the amounts actually yielded by the protein. The determinations of the monamino-acids by Fischer's method are doubtless comparable within certain limits, if sufficient care is exercised in conducting the analysis. The quantities of these amino-acids recovered are unquestionably less than those actually present, for esterification is never complete and the losses incident to the separations by fractional crystallization are not inconsiderable. Under uniform conditions, however, losses are nearly uniform and the figures representing the quantities of amino-acids found give a good idea of differences and similarities between the different proteins. Such figures are in most cases comparable to within perhaps one per cent. of the protein, and probably represent about seventy-five per cent. of the total quantity of the amino-acids which are determined that were originally formed by hydrolysis, providing that these aminoacids are first subjected to two well-conducted esterifications. Most uncertainty attaches to the results obtained for valine and serine, which are separated from associated substances with such difficulty that the determinations of them must be regarded as simply qualitative. Alanine also is difficult to separate in a condition fit for weighing, and no importance is to be attached to differences in the amount of this amino-acid unless these are pronounced.

A very extensive experience, however, with determinations, of arginine, histidine and lysine has convinced me that it is possible to make quantitative determinations of these bases which are very accurate. The results of these determinations can be controlled by comparing the amount of nitrogen contained in the quantities found with that precipitated by phosphotungstic acid under definite conditions which have been worked out in my labora- 
tory. The amount of ammonia yielded by hydrolysis can be determined with such accuracy that differences of only a very few hundredths of a per cent. occur between determinations made on different preparations of one and the same protein. These four determinations are the most reliable that we now have for comparing proteins with one another, and make it possible to detect differences between them which would otherwise escape notice.

Glutaminic acid can be determined in most cases with a close approximation to its true amount, but there are some proteins, especially those from leguminous seeds, from which it is not easily obtained. Experience has shown that by the ester method alone about seventy-five per cent. as much glutaminic acid is usually obtained as by direct separation as the hydrochloride. It is possible, therefore, to control to a certain extent the results of direct determinations by comparing them with those obtained on a larger scale by the ester method.

Although the methods available for thus quantitatively analyzing the products of protein hydrolysis leave much to be desired, it must not be forgotten that only recently have we been able to make any comparison whatever of the proportion of these products.

A striking feature of these analyses, to which Professor Chittenden directed attention in his address before this society last January, is that the total quantity of the substances determined falls far short of one hundred per cent. The majority of successful analyses foot up between sixty and seventy per cent, and of this a part is made up of water which has been introduced by hydrolysis. Calculation shows this amount of water to be approximately equivalent to the losses that may be assumed to occur through incomplete esterification and separation of the acids, so that the summation of well-conducted analyses may be taken as representing somewhere. near the total quantity made up by all the different substances determined.

Nothing is known of the undetermined residue which forms from twenty-five to thirty-five per cent. of the protein. There is no reason to believe that, in the seed proteins, undetermined carbohydrate forms any part of this, for those proteins which give no Molisch reaction give no higher summation than do those that do.

If the amount of nitrogen contained in the quantities of the amino-acids stated in the analyses is subtracted from the total nitrogen of the protein, it is found that this undetermined nitrogen forms about fourteen per cent. of the undetermined part of the protein. This is a higher proportion of nitrogen than is found in any of the monamino-acids that are known to be yielded by proteins, except glycocoll, alanine, serine and tryptophane, even if the proportion of nitrogen is calculated for them as united with one another in polypeptide union. It is improbable that this undetermined residue is made up of these four amino-acids, and we may expect to find still undiscovered substances among the protein decomposition products.

\section{COMPARISON OF THE PROTEINS OF DIFFERENT} SEEDS

The results of this comparative study of the seed proteins shows that no two seeds are alike in respect to their protein constituents. Similar proteins are found only in seeds that are botanically closely related.

The cereals are alike in the proportion and general character of their proteins. The seeds of each of these, with the probable exception of those of rice, contain a small amount of proteose, albumin and globulin, and relatively considerable quantities of prolamin soluble in alcohol, and 
of glutelin insoluble in neutral solvents. With the exception of the nearly related wheat and rye, the proteins soluble in alcohol from each of the cereals are distinct substances. Although no certain difference has yet been detected between the gliadin of wheat and of rye, their glutelins are not alike.

The leguminous seeds are similar in the general character of their proteins, but marked differences exist between the proteins of the various groups. Thus $L u$ pinus, Vicia and Phaseolus present marked differences in their proteins, whereas the proteins of the species of each genus are very much alike. The proteins of Lupinus luteus and of Lupinus angustifolia differ slightly but in their physical properties are clearly distinguished from any of the other seed proteins. Although similar proteins are obtained from the horse bean, lentil, pea and vetch, these are distinctly different from the proteins obtained from other leguminous seeds. These seeds are not alike, however, in the proportion of their several proteins. The chief protein of Phaseolus vulgaris appears to be identical with that of Phaseolus radiatus, but the small amount of other protein was found to be different in properties and composition in each of these seeds.

The cow pea (Vigna) and soy bean (Glycine) contain distinctly different proteins which, however, are similar to but different from those of Vicia. The globulins of the seeds of Corylus and Juglans arè much alike, but not identical, while those from Juglans regia, nigra and cinerea, so far as they have been compared, show no differences. The proteins of other seeds show marked differences, but the botanical relations of these seeds are not such as to permit of further discussion of this subject.

Although the data for generalizations are'as yet few, those that are available plainly indicate a close connection between the chemical constitution of the seed proteins and the biological relations of the plants producing them.

That similar differences exist between homologous proteins of different species of animals is becoming evident from the facts which are gradually accumulating, and these strongly suggest a chemical basis for the multitude of diverse forms of animal and vegetable life.

\section{Connecticut Agricultural \\ Experiment Station}

Thomas B. Osborne

\section{THE FINANCIAL STATUS OF THE UNIVER- SITY PROFESSOR IN GERMANY 1}

ORGANIZATION OF GERMAN UNIVERSITIES

ALL the German universities are government institutions. Like the primary schools and the gymnasia, the university is part of the educational system of that German state in which it is located. The professors are officials of the sovereign, and the major part of the university revenues are derived from the state treasury. The government of the university is, in the last resort, in the hands of the sovereign's Minister of Education, who in the constitutional monarchies is responsible to the Chambers, and in Mecklenburg-Schwerin, to the Grand Duke.

The university is thus under the control of the state Parliament and, according to the laws enacted by it, under the immediate supervision of the Minister of Education. The university budget must be passed each year by the Chambers; the creation of a new chair can only be by parliamentary approval. The appointment of professors rests with the sovereign or his minister, and the scheme of instruction together with

\footnotetext{
${ }^{1}$ Extracted and abridged from Bulletin number two of the Carnegie Foundation for the Advancement of Teaching. See also the issue of Scrence for July 24.
} 